\title{
Elementos que conforman la sociedad de la información
}

\author{
Joel E Studillo García \\ Centro de Investigaciones sobre América del Norte. \\ Universidad Nacional Autónoma de México. \\ Email: ejoel@ servidor.unam.mx
}

\begin{abstract}
RESUMEN
El concepto de sociedad de la información comenzó a utilizarse durante la década de los años sesenta y ha venido teniendo cada vez más importancia en el ámbito bibliotecológico. En el presente artículo se analiza el surgimiento de este concepto desde la perspectiva de diversos autores: Fritz Machlup, Marc Porat, Yoneji Massuda y Manuel Castells, quienes entre otros analizan lo que es la sociedad de la información desde los aspectos económico, tecnológico, cultural, ocupacional y global

Palabras clave: Sociedad de la Información, Sociedad Postindustrial, Sociedad del Conocimiento, Tecnologías de Información, Marc Porat, Manuel Castells, Yoneji Massuda, Daniel Bell.
\end{abstract}

\section{ELEMENTS WHICH CONFORM THE INFORMATION SOCIETY JOEL ESTUDILLO-GARCÍA}

\begin{abstract}
The concept of information society began to be used during the 60 's and has been gaining more and more importance in the library science field. This paper analizes the rising of the concept from the perspective of authors like Fritz Machlup, Marc Porat, Yoneji Massuda and Manuel Castells who examine the information society from the economical, technological, cultural, occupational and global points of view.
\end{abstract}

Key Words: Information Society. Post-Industrial Society, Knowledge Society, Information Technologies, Marc Porat, Manuel Castells, Yoneji Massuda, Daniel Bell.

\section{SOCIEDAD DE LA INFORMACIÓN}

xisten muchas interrogantes acerca de dónde, cuándo y quién inventó el uso - del término sociedad de la información. Algunos autores asumen que esto tuvo lugar, primero, en Estados Unidos y que puede ser ubicado a principios de la década de los sesenta con un trabajo de Machlup. ${ }^{1}$ Posteriormente, en 1971,

1 Fritz Machlup, TheProdutionandDistribation ofKnowkedgein theUniteed States New Jersey, Princenton University, 1971. 
D aniel Bell publicó ElAdkenimientodela SociedadPostindustrial, ${ }^{2}$ y unos años después, en 1977, Marc Porat publicó LaEconomáadelaInfomaciónenEstadosUnidos ${ }^{3}$ mientras que en Japón, Y oneji Masuda daba a conocer su trabajo titulado Lasodedadinfomatizada comosciedad posindustrial, en 1980.4

A partir de los años sesenta, aparece una nueva sociedad caracterizada por el incremento delainformación, como una definición del mundo moderno y se crea un nuevo paradigma que interpreta el desarrollo social con base en el uso y el empleo de tecnologías de información. El concepto sociedad de la información implica muchas suposiciones acerca de lo que está cambiando, y de cómo este cambio es efectivo.

Actualmente la idea de una sociedad de la información es analizada desde dos perspectivas históricas. Por un lado están aquellos que proclaman una nueva organización de sociedad surgida del pasado; en este grupo se encuentran exponentes del posindustrialismo, el postmodernismo y el desarrollo informacional. También hay estudiosos que ponen énfasis en la continuidad, como Anthony Giddens 5 y Jurgen Habermas. ${ }^{6}$ Las dos posturas coinciden en que la información es una parte importante del mundo contemporáneo.

Antes de analizar los diferentes enfoques para entender las tendencias sobre esta sociedad, es necesario examinar las definiciones que se refieren ala sociedad dela información, y el significado que tiene este término cuando se refiere a una sociedad de la información, así como los criterios que se ofrecen para distinguir esta sociedad de otras. D esdela perspectiva deWilliam J. Martin ${ }^{7}$ y Frank Webster, ${ }^{8}$ es posible distinguir cinco elementos que nos pueden ayudar a describir qué es una sociedad de la información; éstos son:

1. Elemento tecnológico

2. Elemento económico

3. Elemento ocupacional

4. Elemento tiempo-espacio

5. Elemento cultural

A continuación describiremos detalladamente en qué consiste cada uno de éstos.

2 D aniel Bell, ElAdweimientodelaSociedadPostindustrial. UnIntentodePrognosisSoial, Madrid: Alianza, 1976.

3 Marc Uri Porat, TheInfomationEconamy: DefinitionandMeasurement. U.S.: D epartment of Commerce, 1977.

4 Y oneji Masuda, Lasocieladinfomatizadacomosociedadposindustrial, Madrid: Fundesco Tecnos, 1984.

5 Anthony Giddens, Consecuenias dela Modemidad, Madrid: Alianza Universidad, 1994, p. 28.

6 Thomas A. Maccarthey, TheCritical Theory ofJurgen Habemas, Cambridge, Mass: The Mit Press, 1978, $466 \mathrm{p}$.

7 William J. Martin, The Global Information Society, London: Aslib, 1988, p.42.

8 Alvin Toffler, TheThirdWave, New York, William Morrow, 1980. 


\section{Elemento tecnológico}

Algunas corrientes prestan atención a la convergencia e interrelación entre telecomunicaciones y computación. El argumento opera basándose en las siguientes líneas: tecnología barata para el procesamiento y almacenamiento de la información, lo que produce una información extensamente distribuida. La computadora se puede interconectar con otras mediante redes, aspecto que a menudo se compara con la provisión de electricidad, ya que las redes de información pueden estar en todo lugar donde se necesite, tal como las líneas eléctricas que llegan al hogar y centros de trabajo.

Alvin Toffler ${ }^{9}$ y Willam J. Martin sostienen que la tecnología de la información representa el establecimiento de una nueva forma de vida que modifica las actividades de la estructura social.

El aspecto tecnológico utilizado en las actividades de información, ha hecho posible el procesamiento, almacenamiento, recuperación y transmisión de información, y provocado la aplicación de tecnologías de información en todos los ámbitos de la sociedad. El factor principal en todo esto es el uso de las computadoras.

Actualmente el empleo de las nuevas tecnologías de información y comunicación, tanto en el ámbito económico como en el social, seidentifican como las características distintivas de la sociedad de la información.

Sin embargo, autores como William J. Martin y Manuel Castells, ${ }^{10}$ quienes hacen hincapié en esta premisa sobre el empleo de tecnologías de información y comunicación, no son capaces de dar una respuesta real, medible o probable, y esto hace que el empleo de estas tecnologías de información sea impreciso para decir que una sociedad se ha convertido en una sociedad de la información.

William J. Martin, argumenta que hay dos problemas importantes que deben considerarse antes de poder hablar de la instauración de una sociedad de información:

a) Cómo se mide la tasa de innovación tecnológica.

b) Cuándo cesa una sociedad de ser industrial y entra a formar parte de una sociedad de la información.

Frank Webster afirma que "[...]en una era dada, las tecnologías se inventan y luego impactan sobre la sociedad; así pues, la tecnología en estas versiones está privilegiada, sobre todo y sobre todos, y llega a identificar a un mundo, la era del vapor, la era atómica, entre otras." 11

9 Alvin Toffler, TheThirdWave, New York, William Morrow, 1980.

10 Manuel Castells,.La Ciudad Informadional: Temdoǵas dela Infomacón, Reestructuracoón Económica yd ProcesoUrbanoRegjonal, Madrid: Alianza, 1995. 412 p.

11 Frank Webster, Theries of theInformation Sociey, Londres, Routledges, 1995, p. 10. La traducción es mía. 


\section{Elemento económico}

Existe una subdivisión establecida de lo económico en lo concerniente a la economía de la información, Fritz Machlup dedicó mucho tiempo de su vida profesionista a evaluar el tamaño y la amplitud de las industrias de información. Su obra pionera, LaProducciónyDistribuacóndd Conoimiento ${ }^{12}$ fue fundamental para establecer medidas en una sociedad de la información. E ste autor intentó trazar las industrias de la información en términos estadísticos, para lo cual distinguió cinco ramas industriales:

a) Educación, escuelas y bibliotecas

b) Medios de comunicación (radio, televisión, publicidad)

c) Máquinas de información (equipos de cómputo, instrumentos musicales)

d) Servicios de información (leyes, seguros, salud, entretenimiento)

e) O tras actividades de información (investigación y desarrollo)

Trabajando con estas categorías se advierte que cadauna tiene un valor económico y su respectiva contribución al Producto Interno Bruto (PIB). Machlup calculó, hacia principios de los años setenta que el 29\% del Producto Interno Bruto de los Estados Unidos provenía de las industrias del conocimiento, y afirmó que el conocimiento se convierte en pieza fundamental de la economía moderna en la medida en que se déun cambio deuna economía de bienes a una economía delainformación.

Hoy es común argumentar que nos hemos desarrollado en una sociedad cuyas características distintivas son la información y su globalización como los creadores de riqueza. Probablementeel trabajo más conocido y más citado sobre el surgimiento de una economía de la información sea la obra de Marc Porat,13 quien dividió la economía en sectores primario y secundario.

Porat incluyó en el sector primario todas aquellas industrias que hacen utilizable su información en mercados establecidos o en cualquier otra parte donde se le pueda otorgar fácilmente a esa información un valor económico; por ejemplo, en los medios masivos, la educación, la manufactura de computación etcétera. También buscó identificar un sistema secundario de información con actividades tales como investigación y desarrollo dentro de una compañía química, la información producida por entes oficiales para consumo interno, y los recursos bibliotecarios de corporaciones industriales. D e este modo Porat fue capaz de distinguir los dos sectores, y concluyó que el 46\% de la población estadunidense está involucrada en el sector información. Estados Unidos es ahora una economía basada en la información y

12 Fritz Machlup, TheProdution. quat.

13 Marc Uri Porat, TheInfomation quat. 
como tal, una sociedad dondelas mayores y principales áreas de actividad económica son aquellas que producen bienes y servicios de información. ${ }^{14}$

Según Webster "Podríamos tener una sociedad en la cual a través de la medición del Producto Interno Bruto (PIB), la sociedad de la información sea de mayor peso, en relación con los otros sectores de la economía, pero de pocas consecuencias en cuanto a los orígenes y sostenes de la vida política, económica y social; así pues, el tema del valor cualitativo de la información deberálimitarse ala relevanciaa ellos." 15

Según los estudios de Machlup, la contribución de las industrias del conocimiento al PIB en los Estados Unidos, tuvo un incremento de 28.6 a $34.3 \%$ entre 1958 y 1980. Estas econometrías anuncian el arribo de una sociedad de la información. Por otra parte Marc Porat dice que se habla de una sociedad de la información cuando más del 50\% del PIB, es generado por este sector, o cuando el Producto Interno Bruto es superior a los demás sectores económicos. ${ }^{16}$ Colin Clark, ${ }^{17}$ en su obra Las Condiaiones dd Progrezoconómica también comparte esta idea.

\section{Elemento ocupacional}

Una medida del surgimiento de una sociedad delainformación es aquella que enfoca el cambio ocupacional y encuentra que el predominio del empleo yace en el sector de la información. Esto es, cuando el número de oficinistas, profesores, abogados, y otros, sobrepasa el de obreros y trabajadores manuales, y con base en que la definición ocupacional frecuentemente se combina con una medición económica. Marc Porat calculó que en las postrimerías de los años sesenta, un poco menos de la mitad de la fuerza laboral estadunidense se encontraba laborando en el sector de la información. (véase Tabla.1.)

D espués de todo, parece obvio que un trabajo que demanda fuerza física y destreza manual, como la industria y la agricultura, decline para ser sustituido por ocupaciones burocráticas, lo que nos indica la entrada de un nuevo tipo de sociedad en el mercado laboral, donde el conocimiento y lainformación se convierten en modos de producción no materiales.

14 Porat citado por Martin, Stana B., "Information Technology, Employment, and the Information Sector: Trends in Information Employment 1970-1995", en Jamal of theAmerican Socieyfor Information Saience 1998, vol. 49, no. 12, pp. 1054-1058.

15 Frank Webster, qp at p. 13. La traducción es mía.

16 Porat citado por: Reynel Iglesias, Heberto y Vélez Salas, Cecilia, "El sector de la información en México: Políticas e Instrumentos para su D esarrollo Económico”, En Reistainformadón: producción comunicacónysarvicios 1991, vol. 1, no. 3, pág. 4-6.

17 Colin Clark, LasCondianes di ProgesoEconómica vol. 2., 3ạ. ed. México, Alianza, 1980, 266 p. 
Tabla 1

\begin{tabular}{|c|c|c|c|c|}
\hline AÑO & AGRICULTURA & INDUSTRIA & SERVICIOS & INFORMACIÓN \\
\hline 1900 & 35.3 & 26.8 & 25.1 & 12.8 \\
\hline 1910 & 31.1 & 36.3 & 17.7 & 14.9 \\
\hline 1920 & 32.5 & 32.0 & 17.8 & 17.7 \\
\hline 1930 & 20.4 & 35.3 & 19.8 & 24.5 \\
\hline 1940 & 15.4 & 37.2 & 22.5 & 24.9 \\
\hline 1950 & 11.9 & 38.3 & 19.0 & 30.8 \\
\hline 1960 & 6.0 & 34.8 & 17.2 & 42.8 \\
\hline 1970 & 3.1 & 28.6 & 21.9 & 46.4 \\
\hline 1980 & 2.1 & 22.5 & 28.8 & 46.6 \\
\hline
\end{tabular}

Fuente: Marc Porat. Porcentaje de la fuerza de trabajo por sector económico en los Estados Unidos: 1900-1980. en Jaumal of theA meicanSocidyforInfomationSaiene V ol. 49, No. 12, 1998, pp. 1062.

Esta tendencia es reforzada por muchos informes de la O rganización para la Cooperación y D esarrollo Económicos (O CD E). En 1981 y 1986 produjo gráficas sobre el continuo crecimiento de aquellas ocupaciones que conciernen principalmente ala creación y el manejo de información, y a su infraestructura de apoyo. Porat identifica una significativa tasa de crecimiento en la fuerza laboral relacionada con la información en las estadísticas de empleo de Estados Unidos.

Pero la metodología para asignar trabajadores a categonías particulares representa un gran problema, pues los datos estadísticos ocultan el verdadero proceso mediante el cual los investigadores construyen sus propias categorías. Por ejemplo, Porat desarrolló una tipología para localizar ocupaciones involucradas en la información recurriendo a un esquema de tres enfoques, involucrando 400 tipos ocupacionales y lo explica como sigue: "Hay cinco categorías de trabajadores de la información: 1) productores, 2) distribuidores, 3) buscadores de mercado y coordinadores de especialistas, 4) procesadores, y 5) operadores de la información." 18

La primera categoría incluye a aquellos trabajadores cuya actividad primaria es producir y vender conocimiento: científicos, inventores, bibliotecarios, periodistas, profesores y autores. La segunda categoría es la de los trabajadores que agrupan ydiseminan información, y aquellos que mueven ésta entre las empresas y el mercado, investigan y planean el proceso del mercado de la información: gerentes, oficinistas, corredores de información, y otros. La última categoría se refiere a los operadores

18 Porat citado en: Martin, Stana B. qp at. pp. 1056, 1065-1066. 
de máquinas y tecnologías de información que apoyan a las actividades anteriores: operadores de computadoras, instaladores telefónicos, reparadores de medios electrónicos, y otros.

Es éste un intento por distinguir el trabajo no informacional del informacional, con base en el grado con el que cada tipo se involucra con la información; en otras palabras, dice Porat, la categorización es un asunto de juicio, la medida en que los trabajos son informacionales o no.

\section{Elemento tiempo-espacio}

Este concepto de sociedad delainformación que descansa en la economía y la sociología tiene como núcleo la fuerza distintiva de un ámbito espacial. Aquí el enfoque principal está en las redes de información que conectan localidades y en consecuencia, tienen efectos dramáticos en la organización del tiempo y el espacio. Frank Webster identifica cuatro elementos relacionados con la transición hacia una sociedad de la información, que son los siguientes, cito en extenso:

1. La información está ocupando el lugar central como recurso estratégico claveen la economía mundial, de ello se desprende quela organización y recuperación de información es de valor excepcional y atestiguamos que se aplicará en un gran número de actividades.

2. Computación y tecnologías de información suministran la infraestructura que permite que la información se procese y distribuya, facilita las operaciones instantáneas de comercio y monitorea los asuntos económicos y sociales a escala global.

3. Ha existido un crecimiento excepcionalmente rápido del sector comercial de la información en la economía de servicios como medios de comunicación (satélite, cable, video) y el desarrollo de bases de datos en línea, que suministran información instantánea sobre precios de bienes, listas, fluctuaciones de monedas, así como resúmenes de revistas técnicas y científicas, entre otras.

4. La creciente informatización de la economía facilita la integración de las economías nacionales y regionales, efecto inmediato y efectivo del proceso e intercambio de la información; la economía se ha convertido en algo verdaderamente global, sin restricciones de espacio, los límites erigidos por la ubicación geográfica se han venido abajo. ${ }^{19}$

Estas tendencias enfatizan la centralidad de redes de información que vinculan localidades, ciudades, países, regiones y continentes, y hacen posible la globalización de la información.

Actualmente existe una explosión de información que se da a conocer a gran velocidad mediante los flujos de información. Esta es la pauta para creer en un nuevo

19 Frank Webster, qu at, p.18. La traducción es mía. 
tipo de sociedad, donde las cosas suceden en lugares particulares y en tiempos específicos. Según Manuel Castells las características del espacio-tiempo se han transformado con el advenimiento de la sociedad en red.

La restricción del espacio se halimitado y, simultáneamente, el tiempo se ha reducido debido a la fusión entre telecomunicaciones y computadoras. Esta compresión "tiempo-espacio", como la llama Anthony Giddens, incluye a corporaciones, gobiernos e individuos.

El dinamismo de la modernidad deriva de la separación del tiempo y el espacio, y de su recombinación de tal manera que permita una precisa regionalización de la vida social; este fenómeno conecta estrechamente los factores involucrados en la separación del tiempo y el espacio. 20

Las redes de información son una característica especial de las sociedades contemporáneas. Los satélites permiten las comunicaciones instantáneas por todo el mundo y puede accederse a las bases de datos desde cualquier parte y de forma inmediata; de acuerdo con Webster: Los sistemas de computación interconectados son parte rutinaria de los negocios modernos. Cada vez más volumen y velocidad deinformación marcan una nue va sociedad. ${ }^{21}$

\section{Elemento cultural}

El enfoque cultural en una sociedad de la información es quizá el que más fácilmente se reconoce. Todos sabemos que en la trayectoria de nuestra vida diaria existe un extraordinario incremento de la información que circula socialmente; esto es, más información que nunca antes. La televisión se ha expandido de un solo canal y servicio discontinuo a una programación de centenares de canales, lo que ha permitido el mejoramiento eincorporación de tecnologías deinformación, como el cable, los canales satelitales y los servicios computarizados como el teletexto. También la radiotransmisión se ha incrementado mediante el uso de redes. Y no podemos pasar por alto la enorme disponibilidad de títulos de libros y revistas editados en papel y en formato electrónico, todo lo cual testifica que habitamos una sociedad abrumada por los medios de comunicación e información.

La cultura contemporánea es más informativa que sus predecesoras, vivimos inmersos en unainteracción simbólica en donde todo lo que se intercambia y recibe es reconocible. Esta explosión de datos y símbolos significa lo que muchos escritores conciben como la sociedad de la información:

[...]paradójicamente esta fuerte explosión de información guía a algunos autores a anunciar que con la muertedel siglo, hay mas información y me nos significado. ${ }^{22}$

20 Anthony Giddens, Conseuenias.. quat.

21 Frank Webster, Theries... quat. pp. 21-22. La traducción es mía.

22 Ibid p. 22. La traducción es mía. 
Como lo reflejan estos cinco aspectos la idea de una sociedad de la información se reconoce con facilidad, pero definirla es considerablemente más difícil.

Jorge Schemet Reyna, ${ }^{23}$ considera que la sociedad de la información comenzó a gestarse a partir de cuatro postulados básicos que están implicados en una interpretación postindustrial.

En el primer postulado Schemet Reyna considera que la sociedad industrial y sus formas de organización social pasaron hace mucho, y que la sociedad de la información está en un estado de desarrollo.

En este sentido existe un claro acuerdo entre varios autores como Manuel Cazadero, ${ }^{24}$ William D izar, Nick Moore ${ }^{25}$ y Marcos Kaplan, ${ }^{26}$ quienes consideran que las características de la sociedad industrial están declinando, y que está en constante evolución el sector de servicios, dentro del cual las actividades relacionadas con las telecomunicaciones e informática están en continuo progreso.

En el segundo postulado de Schemet la presencia de la información se interpreta como prueba de que la idea de sociedad de información tiene validez. Muchos exponentes como D aniel Bell, ${ }^{27}$ Y oneji Masuda y Marc Porat, reconocen la existencia e importancia de tal sociedad desde una perspectiva económica, tecnológica, educativa y laboral entre otras.

En el tercer postulado de Schemet Reyna el postindustrialismo asume un desarrollo social secuencial, se presume que todas las naciones del mundo están en un único sendero de evolución que se da de la siguiente manera; de la cacería y recolección se pasaa la agricultura, posteriormente ala sociedad industrial y se continúa hacia una sociedad de servicios; la sociedad de la información es imaginada como la culminación de la madurez cultural humana, en el cuarto sector económico.

$Y$ en el cuarto postulado la sociedad de la información se concibe como una continuación de la eraindustrial, yla presencia del capitalismo permanece incambiable.

En el intento por alcanzar una definición generalmente aceptada sobre sociedad de la información se deben tomar en cuenta ciertos puntos:

El progreso continuo de las sociedades hacia estados más avanzados de desarrollo tecnológico y económico.

La necesidad deincluir en la definición de sociedad dela información aspectos filosóficos y económicos, tales como la calidad de vida en una sociedad altamente tecnocrática.

23 Jorge Schement Reyna, CompetingV isions, Complex Realities Social Aspets of theInfomation Socity, New Jersey: Ablex Publishing, 1987, p. 36.

24 Manuel Cazadero, LasReduaionesIndustriales México: Fondo deCultura Económica, 1996, 229p.

25 Nick Moore, "La Sociedad de la Información", UNESCO Repate Mundial Sdbre Infomadón 1997-1998 New York: UNESCO, 1998, 284 p.

26 Marcos Kaplan, ReuduiónTemdógica: Cienia EstadbyDeechoenlas Primeras Reuduiones Industriales Vd. 1. México: Universidad Nacional Autónoma de México. Instituto de Investigaciones Jurídicas, 1993.

27 D aniel Bell, El Adwerimienta. quat. 
El contexto tiempo-espacio y el hecho de que estamos hablando del futuro más que de los desarrollos actuales, según John Naisbitt ${ }^{28}$ y Alvin Toffler. ${ }^{29}$

A continuación podremos apreciar algunas características de la sociedad de la información desde las perspectivas de Naisbitt y Toffler:

\begin{tabular}{|l|l|}
\hline \multicolumn{1}{|c|}{ J ohn Naisbitt } & \multicolumn{1}{c|}{ Toffler Alvin } \\
\hline $\begin{array}{l}\text { La sociedad de la información es una realidad } \\
\text { económica no una abstracción intelectual. }\end{array}$ & $\begin{array}{l}\text { La información pasa a ser el recurso central } \\
\text { de la economía avanzada }\end{array}$ \\
\hline $\begin{array}{l}\text { Las innovaciones en las telecomunicaciones y } \\
\text { en las tecnologías de la computadora van a } \\
\text { acelerar el paso del cambio al producir el de- } \\
\text { rrumbe de barreras de la información. }\end{array}$ & $\begin{array}{l}\text { El saftuare, la información y las telecomunica- } \\
\text { ciones pueden ser elevados a nivel global. }\end{array}$ \\
\hline $\begin{array}{l}\text { Las nuevas tecnologías de información se } \\
\text { aplicarán al principio a antiguas tareas indus- } \\
\text { triales; después y gradualmente darán origen a a } \\
\text { actividades, procesos y productos nuevos. }\end{array}$ & $\begin{array}{l}\text { Las tecnologías de información y comunica- } \\
\text { ción activan las cosas y nos llevan hacia una } \\
\text { economía instantánea en tiempo real. }\end{array}$ \\
\hline $\begin{array}{l}\text { En esta sociedad de intensiva alfabetización, } \\
\text { el sistema educativo producirá individuos me- } \\
\text { jor preparados. }\end{array}$ & $\begin{array}{l}\text { El conocimiento, a veces nada más como in- } \\
\text { formación y datos, puede utilizarse como sus- } \\
\text { tituto de otros recursos }\end{array}$ \\
\hline $\begin{array}{l}\text { La tecnología de la nueva era de información } \\
\text { no es absoluta, tendrá éxito o fracasará de } \\
\text { acuerdo con el principio de alta tecnología. }\end{array}$ & $\begin{array}{l}\text { La información reduce la necesidad de mate- } \\
\text { rias primas, trabajo, tiempo, espacio y capital. }\end{array}$ \\
\hline
\end{tabular}

Sin embargo no debemos pasar por alto algunos de los elementos actuales, como podrían ser los cambios económicos estructurales, y más particularmente la distribución de las fuerzas de trabajo; el incremento de los recursos de información; una aparición creciente de la necesidad de difundir literatura de computadoras; la amplia difusión de las tecnologías de información, y la intervención gubernamental de apoyo a las tecnologías de computación, microelectrónica y de telecomunicaciones.

En la sociedad de la información la calidad de vida, así como las perspectivas de cambio social y desarrollo económico, dependen cada vez más de la información y su explotación.

28 John Naisbitt, Gldbal Paradox: theBigger theWoddEconomy. theMarePonefuil its Smallet Playes New York: William Morrow, 1994.

29 Alvin Toffler, El Canbiodd Podr. ConoimientoBienetaryV idenaiaend Unbral da SigoXXI. Barcelona, Plaza \& Janes, 1990. 
En esta sociedad los estándares de vida, los patrones laborales, el sistema educativo y el mercado están marcadamente influenciados por los avances de la información y el conocimiento; esto es evidenciado por un incremento en los productos y servicios de información, comunicados a través de los medios electrónicos.30

La rapidez en la circulación de la información se debe en gran medida al desarrollo de tecnologías de información y comunicaciones, las que se perfilan como motores de una revolución en todas las actividades económicas, educativas y de entretenimiento. Pero la característica fundamental de esta nueva sociedad de información es su entorno global; es decir, el hecho de que pueden verse sus efectos multiplicadores sobre los procesos que la promueven: comunicaciones, tecnologías de información y redes de comunicaciones que difunden la cultura y la economía, entre otras, y que han sido desde hace tiempo el objeto de creciente consideración.

$\mathrm{D}$ aniel Bell fue uno de los primeros pensadores que abordaron el tema de la sociedad de la información al analizar cómo estaban cambiando las actividades en los sectores económicos de la industria y los servicios, y observar que las actividades relacionadas con la información estaban en constante aumento, además de que empleaban a un gran número de personas y generaban un alto porcentaje del PIB. Bell consideraal sector de la información como el motor de cambio que hará posible una sociedad postindustrial, en la que podrá observarse un cambio en la economía de la producción de bienes hacia una de servicios basados en la información, en la que profesionistas y técnicos reemplazarán a los trabajadores de cuello azul (obreros), y donde el conocimiento se convertirá en pivote de la innovación y la elaboración de políticas, y donde las tecnologías de información serán la clave para continuar en un constante desarrollo.

Para Castells la creación y el surgimiento del sector de la información han causado una revolución silenciosa conformada por la industria de la información, los medios, los servicios, los productos y la industria de procesamiento de la información, como también el manejo de las tecnologías de información y comunicación. ${ }^{31}$ Este autor afirma que el tercer sector económico (servicios) sentó las bases para el desarrollo de un cuarto sector, que es el dela información, pero para que esto pueda existir deben antes darse tres condiciones que son:

1. Las fuentes deinformación y el crecimiento del conocimiento deben extendersea la actividad económica a través de los procesos de información.

2. Laactividad económica de la producción de serviciosyla disminución del empleo agrícola, seguida por una caída del empleo manufacturero, deben generar para el sector de servicios una gran proporción de empleos.

30 William J. Martin Op at p. 42 La traducción es mía.

31 Manuel Castells, LaEradelaInfomaáón: Economá, SoięadyCultura, VdumenI. LaSocięadRee, México, Siglo XXI, 1997. 
3. La nueva economía debe incrementar la importancia de ocupaciones que exijan una alta información y contenidos de conocimientos o profesiones administrativas y ocupaciones técnicas, las cuales pueden crecer mucho y constituir una nueva estructura social. ${ }^{32}$

El desarrollo de un posible cuarto sector económico, lo conforman las actividades de información y el advenimiento y los avances de la tecnología tanto de información como de comunicación, que han llegado a adquirir el carácter de agentes revolucionarios.

Yoneji Masuda, uno de los más sobresalientes investigadores japoneses que trabajan sobre este tema, considera que en una sociedad de la información el sector de actividad más importante está constituido por la industria de la información, en su más amplio sentido. En esta sociedad, el peso principal de la actividad económica descansa sobre la información.

Laera delainformación es el período durante el cual tienelugar unainnovación, se convierteen lafuerza latente de la transformación social, capaz de acarrear una expansión en la calidad y en la cantidad de información y un aumento en gran escala del almacenamiento de la información. ${ }^{33}$

Masuda opina que la sociedad dela información será algo inevitable en un futuro no muy lejano.

Por su parte, en su intento por definir lo que es una sociedad de la información, William J. Martin dice que deben considerarse ciertos puntos, como son: la calidad de vida en una sociedad; el concepto temporal y el hecho de estar hablando del futuro, más que de los desarrollos actuales; el sistema educativo y el aspecto económico alcanzados con base en las actividades relacionadas con la información

En la sociedad de la información, la calidad de vida, así como las perspectivas de cambio social y desarrollo económico dependen cada vez más de la información y su explotación. ${ }^{34}$

Según William J. Martin los criterios que deben considerarse para el desarrollo de una sociedad de la información son:

a) Teendóġa Ésta es la clave para la capacitación. Una aplicación y difusión de tecnologías de información en oficinas, fábricas, escuelas y el hogar.

b) Soial. La información como un factor para mejorar la calidad de vida. Una extensa conciencia de la información y acceso a usuarios de información de alta calidad.

c) Económica Lainformación como una clave del factoreconómico: servicio, comodidad, una fuente de valor agregado y empleo.

d) Poítica La libertad de información nos lleva a un proceso político caracterizado por el aumento de la participación y la conciencia.

32 Manuel Castells and Yuko, Aoyama, qpàt p.6.

33 Yoneji Masuda quat p. 20.

34 William J. Martin qp àt p.42. La traducción es mía. 
e) Cultural. El reconocimiento del valor cultural delainformación a través de la promoción de sus valores en interés del desarrollo nacional e individual. 35

Heberto Reynel considera que la sociedad de la información es aquella en la que la mayor parte de la población económicamente activa labora en actividades relacionadas con producción, comercialización y sistemas de información. A simismo, estas actividades relacionadas con la información generan la mayor parte del PIB en la economía de los países que cuentan con un desarrollo de tecnologías de información y comunicación, como es el caso de Estados Unidos de Norteamérica y otros países desarrollados.

\section{MODELOSREPRESENTATIVOSDE LA SOCIEDAD DE LA INFORMACIÓN}

Un modelo es una construcción racional que para ser eficaz debe ser construido para representar ciertos factores abstractos de un conjunto de fenómenos empíricos, que además deben corresponder a una teoría validada de un conjunto de fenómenos. Los elementos característicos de un modelo son:

a) Construcciones realizadas por el investigador para comprender la realidad desconocida y compleja, y para hacerla aprehensible. El investigador utiliza el modelo para representar el fenómeno estudiado estableciendo un conjunto de variablesy relaciones entre esas variables, y hacer con ese modelo un postulado de interpretación del mundo.

b) El modelo pretenderepresentar la realidad descrita simplificándola. Los modelos dan una imagen sintética teniendo en cuenta no todas las variables que se dan en losfenómenos sociales sino sólo las más importantes, ya que representa conceptualmente la realidad demanera perfecta es imposible. La representación puede ir desde un gráfico hasta una forma matemática, pero su eficacia radica en la manera de representar los rasgos abstractos de un fenómeno y en aportar un sistema formal pertinente para tales rasgos.

c) Los modelos son un conjunto de enunciados teóricos sobre las relaciones entre las variables que caracterizan a un fenómeno.

d) Los conceptos básicos que tienen como mínimo en común todos los modelos son: emisor, mensaje y receptor, que sirven para comprender la realidad que pretendemos explicar.

Con base en esta definición a grandes rasgos de lo que es un modelo, trataremos de representar cómo conciben ala sociedad de lainformación algunos autores como Marc Porat, D aniel Bell, Manuel Castell y Y oneji Masuda.

Ilid p. 40. La traducción es mía. 


\section{Inestigadón Biblidteedógica v. 15 N o. 31 julio/ diciembre de 2001}

\section{Marc U ri Porat}

Marc Porat es considerado un pilar en el estudio de la sociedad de la información y no puede pasar inadvertido en la elaboración de un trabajo con esta temática. Su obra InfomationEconomy, se dio a conocer en 1977 y está enfocada al análisis económico de la información en Estados Unidos. El autor fue el primero en utilizar el término sociedaddelainformacóny en tratar de determinar la extensión en la producción, procesamiento y distribución de los bienes de información y de servicios que contribuyeron al Producto Nacional Bruto (PNB). También seleccionó las actividades de información registradas en las Cuentas Nacionales de Estados Unidos so bre los sectores económicos correspondientes a industria, servicios y gobierno, para conformar un sector económico correspondiente a la información.

Porat analizó todas las profesiones que aparecían clasificadas en las estadísticas laborales oficiales relacionadas con el manejo de información, y definió a los 'trabajadores del conocimiento' como aquellos cuyo resultado de trabajo era la producción, distribución o manipulación de información.

Sin embargo al analizar las clasificaciones de profesiones se enfrentó con el problema de que las estadísticas oficiales no permiten, al menos por ahora, medir directamente quién es un trabajador de la información. Por ello consideró que el problema se resolvía clasificando las profesiones de acuerdo con aquello que esté relacionado con el manejo de información yordenándolas en cinco grandes categorías:

1) Producción de la información

2) Distribución de la información

3) Análisis de mercados y coordinación de la información

4) Procesamiento de la información

5) O peración de la maquinaria informacional

Porat considera que la información está constituida por datos que han sido organizados y comunicados; y que la actividad de información incluye todos los recursos consumidos en la producción, procesamiento y distribución de bienes y servicios de información.

En su investigación Porat analizó las características del Producto Interno Bruto (PIB) generado por actividades de información y el número de personas ocupadas en este sector, pero también incluyó máquinas, edificios y otros bienes y servicios, desde computadoras hasta mimeógrafos, como elementos que integran la economía de la información.

A simismo analizó diversos censos económicos de Estados Unidos y fue seleccionando actividades relacionadas con la información para agruparlas posteriormente en un nuevo sector, al cual llamó setoraratemanioo setordelainfomaión. Su informe concluye que las actividades de información en la economía de Estados Unidos representaban el 46\% del Producto Nacional Bruto de 1967; mientras que la mitad de la fuerza laboral que percibía el $52 \%$ del ingreso total tenía un empleo relacionado de alguna forma con la información. 
También clasificó las actividades de información en primarias y secundarias, en tanto que el sector de actividades primarias fue definido de modo que incluyera servicios deinformación eintercambio de servicios en un mercado, y el sector secundario abarcara grupos que tenían una organización que proporcionaba servicios de información, pero que nunca los vendía a un mercado estable.

Finalmente concluyó que sí se ha dado el cambio de una economía de servicios a una de información, y que ésta ha venido incrementándose recientemente de manera rápida con el empleo de tecnologías de información y comunicación aplicadas a las actividades laborales, educativas y recreativas.

En el siguiente modelo pueden apreciarse los elementos que intervienen para conformar la sociedad de la información (ver dagama 1) ${ }^{36}$

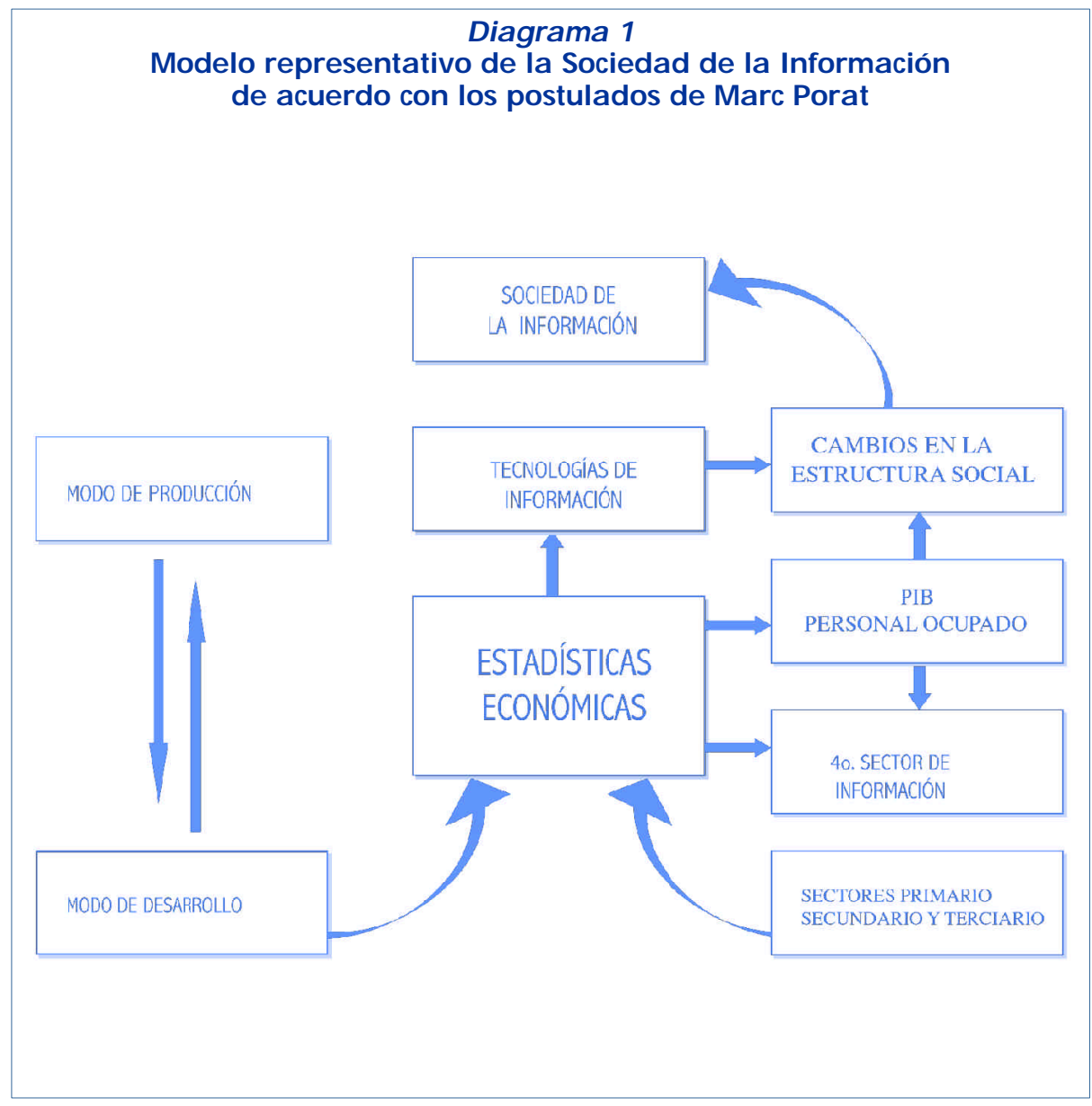

36 Los diagramas son una interpretación sobre cómo conciben los autores expuestos la sociedad de la información. 


\section{Investigadón Biblidteedógica v. 15 N o. 31 julio/ diciembre de 2001}

\section{Daniel Bell}

Entre aquellos que suscriben la noción de que un nuevo tipo de sociedad está surgiendo gracias a la fusión de computadoras, telefonía y televisión para proporcionar una comunicación más rápiday de mayor alcance, se encuentra D aniel Bell, quien la llamó "sociedad postindustrial". En su libro El Advenimientodela SociedadPostindus trial, plantealos cambios tecnológicos de las sociedades avanzadas que se habrían de ver a finales de los años setenta y a las que impactaría el arribo de las tecnologías electrónicas, como las computadoras, que parecieran estar en todo lugar. ${ }^{37}$

Bell sostiene que el ser humano se está acercando a una sociedad postindustrial caracterizada por el empleo de la información, y aduce que información y conocimiento son cruciales para la sociedad postindustrial. Según él todos los profesionistas en activo son trabajadores de la información: abogados, maestros, ingenieros, programadores en computación, analistas de sistemas, médicos, arquitectos, contadores, bibliotecarios, periodistas, trabajadores sociales, enfermeras y clérigos, entre otros. Para los trabajadores profesionistas y de oficina, la tarea es crear, pensar y distribuir la información.

El punto crucial de una sociedad postindustrial es que el conocimiento y la información se convierten en los recursos estratégicos que transforman a la sociedad de la misma manera que el capital y la mano de obra han sido los recursos estáticosy de transformación de la sociedad industrial. 38

Bell considera que los Estados Unidos guían al mundo haciaun nuevo tipo desistema, y establece que es posible pasar de las sociedades preindustriales a las industriales, y de ahí a las postindustriales. "Si la sociedad industrial se define como productora de bienes y la manufactura es central en su conformación, entonces E stados Unidos ya no es más una sociedad industrial." 39 Su evidencia se basa en la consulta de estadísticas laborales de Estados Unidos que muestran un crecimiento del sector servicios y una declinación en el sector manufacturero.

No es difícil aplicar los términos de Bell a los periodos históricos; por ejemplo, en la $\mathrm{G}$ ran Bretaña- que a principios del siglo XVIII era preindustrial y agrícola, y a finales del siglo XIX era industrial, ahora, al final del siglo XX, muestra signos de postindustrialismo- predominan los servicios.

La sociedad postindustrial surge solamente de los cambios en la estructura social, incluida la economía, y el sistema ocupacional y el de estratificación, que excluyen política y tópicos culturales.

Por eso su obra cuenta o relata los cambios que ocurren solamente en un sector de la sociedad.

37 D aniel Bell, LaTemdoǵa dela Commicaoón parabienoparamal. Harvard: Biblioteca de Harvard de Administración de empresas, 1979, p. 6.

38 Daniel Bell, qp at. p. 7. La traducción es mía.

39 A.S. D uff D uff, A. S. "D aniel Bell theory of the Information Society". En Jamal of Information So dey, Vol. 24 núm. 6, 1998 pp. 373-399. La traducción es mía. 
El autor sostiene que mientras que en las sociedades preindustriales predominael sector agropecuario, en las industriales la norma es el trabajo de transformación y en las postindustriales el dominio lo tiene el sector servicios. El factor crítico es moverse de una sociedad a otra, y en esto el gran motor consiste en conseguir lo más con el menor esfuerzo. Esto es un principio de racionalización, conforme avanza este proceso el hombre entra en la era industrial, en la que comienza a predominar el sector industrial y siempre está presente el principio de conseguir "más y pagar menos", y donde más y más técnicas especificas guían, a su vez, incrementos sostenidos en la productividad.

El sector servicios es una categoría mezclada que incluye no solamente a los trabajadores profesionistas y técnicos sino también a los de transporte y comercio.

Los trabajadores de cuello azul, en el sector servicios, están más que superados por los de cuello blanco y el desarrollo tecnológico como la automatización, asegurarían que continuarían creciendo, esto es, ir hacia el postindustrialismo. 40

Las características de una sociedad postindustrial, según este autor son:

1. D eclinación en el número de gente empleada en la industria.

2. Incremento en la producción industrial, en virtud de la racionalización, acompañando esta declinación.

3. Incrementos continuos que producen mayor riqueza.

4. Una presión de suministros que jamás tiene fin y crea nuevas oportunidades para el trabajo en el sector servicios.

Bell observa una marcada declinación del empleo en los sectores primario y secundario, que se estabiliza por una expansión laboral en el sector terciario o de servicios. Es necesario enfatizar que el sector servicios implica, en el sentido real, la transferencia de empleos de un sector a otro, y que el empleo de automatización va a disminuir físicamente la mano de obra, lo cual le da a la sociedad más amplitud para recibiry expandir continuamente sus riquezas. Los recursos adicionales desarrollan nuevas necesidades eincrementan el sector servicios como hoteles, turismo, salud y educación, entre otros.

En breve los servicios incrementarán la mayor riqueza que dejan laindustria y la agricultura, pero no existe temor de que los trabajos en los servicios por sí mismos habrán de automatizarse. ${ }^{41}$

Bell explica con un número de observaciones conexas el carácter que reviste la vida en diferentes épocas. La vida en la era preindustrial era un juego con la naturaleza y había que luchar a brazo partido. En la era industrial, con el predominio de la máquina, la vida era un juego contra la naturaleza artificial. En contraste con ambas, en la sociedad postindustrial la vida se basa en los servicios, es un juego entre personas y lo que cuenta no es la fuerza viva, el poder o la energía, sino lainformación.

40 Ilid La traducción es mía.

41 Daniel Bell, qp at. p. 376. 
Las nuevas tecnologías de información y comunicación son el agente de cambio de la vida moderna y de sus estructuras sociales y han transformado la naturaleza de las ocupaciones y las relaciones de la gentey se han constituido en el medio del crecimiento económico. Las nuevas tecnologías de las comunicaciones y computadoras constituyen el fundamento de la sociedad postindustrial, que es una tecnología intelectual cuyas raíces y modalidades de aprendizaje son muy distintas a las de la tecnología anterior.

Según Bell las trayectorias subyacentes de las nuevas tecnologías son:

Tecnologías transformadoras

Tecnologías extensivas

Nichos

\begin{tabular}{|l|l|l|}
\hline \multicolumn{1}{|c|}{$\begin{array}{c}\text { Tecnologías } \\
\text { tra nsforma doras }\end{array}$} & \multicolumn{1}{c|}{ Tecnologías extensivas } & \multicolumn{1}{c|}{ Nichos } \\
\hline $\begin{array}{l}\text { La computadora es una tecno- } \\
\text { logía transformadora que nos } \\
\text { permite hacer cálculos, alma- } \\
\text { cenar información, realizar si- } \\
\text { mulaciones, diseño, modelos } \\
\text { por computadora para la pro- } \\
\text { ducción, etcétera. }\end{array}$ & $\begin{array}{l}\text { Las redes son una tecnología ex- } \\
\text { tensiva frente a las computadoras } \\
\text { aisladas. Se cuenta con redes inter- } \\
\text { nas en las compañías y entre diver- } \\
\text { sas empresas. Además, hoy en día } \\
\text { se cuenta con el internet y sus mi- } \\
\text { les de sitios. }\end{array}$ & $\begin{array}{l}\text { La aplicación de programas } \\
\text { puede ser con base en: ho- } \\
\text { jas de cálculo financieras, } \\
\text { juegos, programas de salud, } \\
\text { etcétera y para necesidades } \\
\text { específicas. }\end{array}$ \\
\hline \multicolumn{2}{|l}{}
\end{tabular}

Una tecnología transformadora efectúa un cambio revolucionario en cuanto a su repercusión social, mientras que las extensivas amplían la esfera de influencia. La aplicación de los nichos ha sido planeada y especializada para tareas especificas.

Con el surgimiento de una sociedad postindustrial, el material de trabajo para la mayoría de la gente es la información; por ejemplo, los banqueros manejan transacciones monetarias, los publicistas crean y transmiten imágenes y símbolos, los profesores comunican conocimiento, el trabajo en los servicios seguramente es trabajo en información para reestratificar esto. En la tipología de Bell, es posible distinguir tres tipos de trabajos: extractivos, de fabricación y actividades de información. 42

El balance delos sectores económicos ha cambiado con los siglos así que en la sociedad postindustrial, el grupo predominante de empleados está conformado por trabajadores de la información.

Primero, que todo el trabajo de información es una actividad de cuello blanco en la que se trata más con personas que con cosas. Segundo, dentro de los trabajos profesionistas del sector servicios hubo un incremento de más del $30 \%$ de la fuerzalaboral a fines de los años 80 . Tercero, el núcleo de la sociedad postindustrial está en sus servicios técnico-profesionistas, por lo que científicos e ingenieros constituyen el grupo clave de esa sociedad. Cuarto, si se trata de un segmento particular de servicios es 
decisivo para la sociedad postindustrial contar con un amplio grupo de profesionistas en salud, investigación, educación, y gobierno. Esto se manifiesta con la expansión de la fuerza laboral de profesionistas en las universidades, instituciones de investigación y el gobierno. ${ }^{43}$

En cuanto al trabajo profesionista, lo más importante es hasta donde se involucró Bell, el papel de los intelectuales, porque promueven la información y el conocimiento. El incremento de profesionistas significa no solamente información circulante sino también que la sociedad sufre decisivos cambios cualitativos, una razón de esto es que los profesionistas siendo expertos en conocimiento tienen disposición para la planificación. "Todas las sociedades están colocadas en la mismajornada de desarrollo, la cual debe seguir la ruta de la sociedad postindustrial." 44

Bell divide el empleo en tres sectores separados: primario, secundario y terciario; es decir, agrícola industrial y de servicios, pero decisivamente los vincula entre sí argumentando que los servicios son dependientes de los resultados o producciones de los otros dos sectores. Pero no sólo emprende la clasificación del empleo en diferentes sectores como indicativo del surgimiento de la sociedad postindustrial sino que también lo hace operar como una teoría de causa, la cual está apoyada en categorías estadísticas. Sin embargo, en la situación presente existe la suposición de que la creciente productividad en los sectores primario y secundario constituye el motor que impulsa el proceso de transformación hacia una era postindustrial y un dominio en los servicios.

Además establece que una sociedad se mueve hacia el industrialismo cuando tiene suficiente riqueza en cuanto a servicios y materiales, y a su vez genera empleo en los servicios, que son la mayoría en el mercado de trabajo y consumen los recursos que se han creado en otras partes. Las premisas de este modelo de sociedad y cambio social sufren un reto cuando se examina la esencia del trabajo en servicios.

D aniel Bell también da su punto de vista respecto del papel que juegan las computadoras y las telecomunicaciones en el desarrollo de la información. La característica distintiva en las nuevas ideas de Bell es la fusión de las tecnologías como el teléfono, la computadora, el fax, el cabley las videodiscos, entre otros, que guiarán hacia una reorganización en los modos de comunicación entre la gente.

El autor comparte la idea sobre la transformación de la vida diaria y social con base en la amplia difusión de las comunicaciones y sostiene que de cualquier forma éstas influirían en la sociedad para originar cambios radicales.

La información se vuelve importante de tres maneras: como sistema de control para la dirección codificada de la producción; como principio de ordenamiento para la programación y otras funciones de registro, como en la administración de sistemas de información, y para las comunicaciones, como en Internet. 45

43 D aniel Bell, qu dit, p. 17.

44 Daniel Bell, qp at, p. 40.

45 A. S. D uff, qu at, p. 389. La traducción es mía. 
Bell afirma que la idea de una sociedad de la información incluye la capacidad científica y los medios para transformar el conocimiento en productos lo que comúnmente se conoce como tecnología de punta. De esta manera puede afirmarse que sólo los Estados Unidos y Japón han entrado en la era de la información. Si la definición precisa el viraje de la manufactura hacia los servicios, entonces $\mathrm{G}$ ran Bretaña, casi toda E uropa $O$ ccidental, los Estados Unidos y Japón han pasado a una sociedad postindustrial. (ver dagama 2)

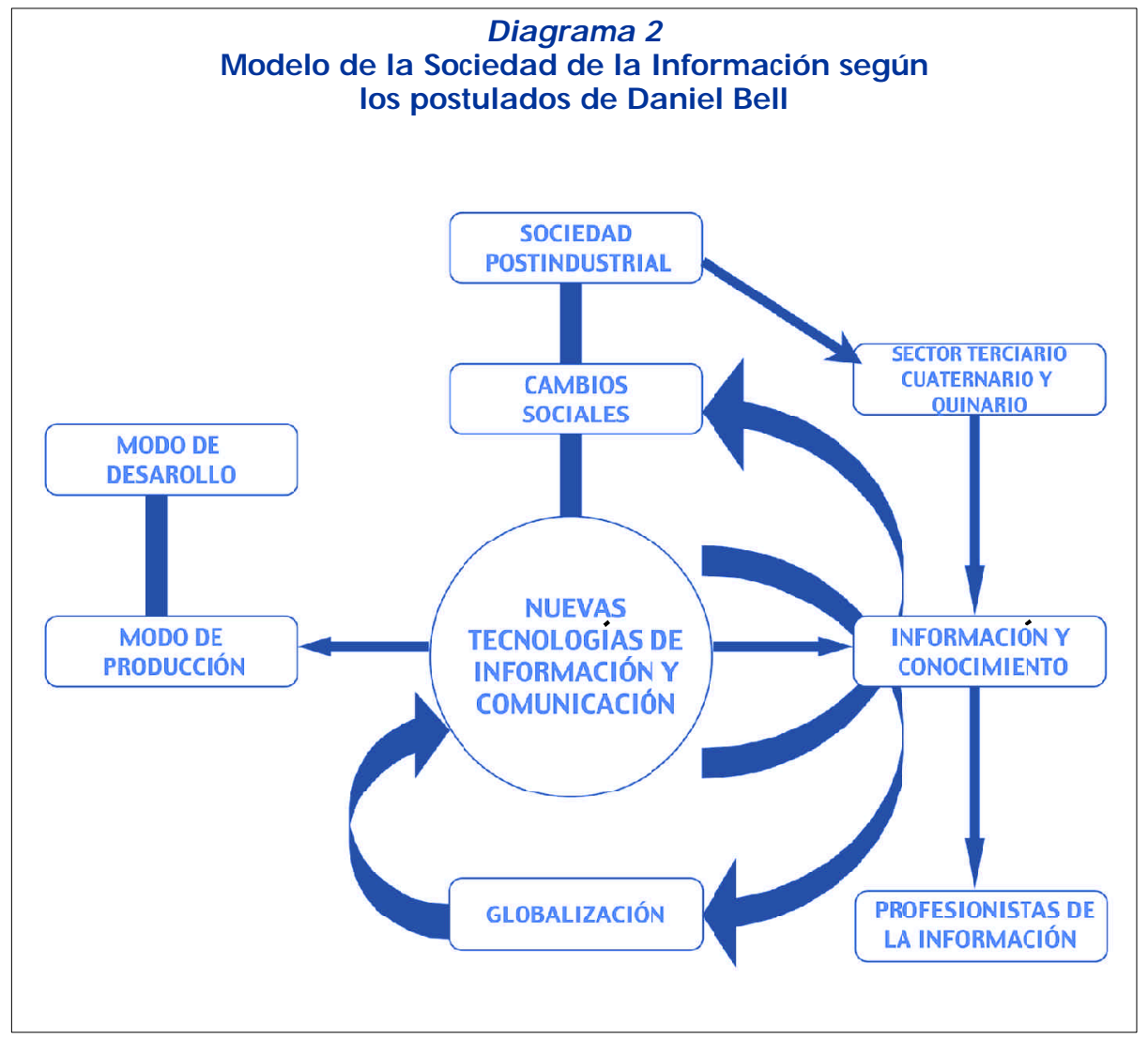

\section{Yoneji Masuda}

Yoneji Masuda es uno de los autores japoneses de mayor renombre que se han ocupado de estudiar el nacimiento de la nueva sociedad surgida a partir de la explotación de la información, las telecomunicaciones y la informática. En su obra LaSo deelad Informatizada comb Socieelad Postindustrial, explica que en una sociedad el sector de actividad más importante está constituido por la industria de la información, y que el peso principal de la actividad económica descansa también en ésta. 
Su visión futurista se basa en el amplio uso de la tecnología de la información y comunicación en gran cantidad de actividades dentro de una sociedad.

En la sociedad global de la información todos los ciudadanos están unidos entre sí por una red global de información y conocimiento, dirigido hacia la formación de una conciencia global, que dará fin a las diferencias entre culturas, intereses y nacionalidades. ${ }^{46}$

Sostiene que la globalidad es un fenómeno nuevo que está surgiendo en todo el mundo, y por tanto no considera a la sociedad de la información como el resultado de la transformación que se está gestando en la sociedad industrial. El cambio que está teniendo la sociedad moderna se basa en la combinación de la tecnología de las computadoras y las comunicaciones. Asimismo considera que este tipo de tecnologías es muy distinto de la existente en las sociedades agrícolas e industriales y que su materia de trabajo es la información.

Este autor hace una breve reflexión acerca de la importancia y las características que tienen estas nuevas tecnologías de la información y afirma que se producirá una transformación social en un doble sentido:

1. La transformación social es el resultado de la innovación en la tecnología social, que en el pasado siempre estuvo relacionada con la productividad física. Esto significa que en el pasado la tecnología se relacionaba con la productividad física para crear bienes materiales.

2. La innovación en la tecnología social no está relacionada con la productividad de bienes materiales sino con la productividad de información, y por ello se esperan cambios en los valores humanos, en tendencias depensamiento, y en las estructuras políticas y económicas de la sociedad.

Plantea que la sociedad de la información es una secuencia de la sociedad industrial actual y opina que el cambio en el futuro será muy diferente.

La base para efectuar esta aseveración radica en que la fuerza conductora motriz que estará detrás de la formación y el desarrollo de la sociedad, serála producción devalores de información, no la devalores materiales. La futura sociedad de la información tendrá que regirse por un marco nuevo analizando el sistema de la tecnología de las computadoras y las comunicaciones, lo que determinará la naturaleza fundamental de la sociedad de la información. ${ }^{47}$

El modelo que plantea Masuda de una sociedad de la información, es que ésta tendrá cambios en los siguientes aspectos: innovación tecnológica, estructura socioeconómica y valores. A continuación describimos los principales elementos que conforman una sociedad de la información según este autor.

1. En la sociedad de la información, la tecnología de la computadora será la innovación tecnológica que constituya el núcleo de desarrollo, y su función más importante será la de sustituir y amplificar la labor mental del hombre.

46 Yoneji Masuda, qp at, p. 15.

47 Yoneji Masuda, qp at, p. 46. 
2. Una revolución de la información, resultante del desarrollo de la computadora, expandirá con rapidez la fuerza de producción de información y hará posible la producción masivay sistematizada deinformación, tecnologíay conocimientos.

3. La unidad productora de información (una infraestructura pública basada en la computadora) que consiste en bancos de datos y redes de información, reemplazará a la fábrica como símbolo social y se convertirá en el centro de producción y distribución de bienes de información.

4. La frontera del conocimiento se convertirá en el mercado potencial y tanto el aumento de las posibilidades para resolver problemas como el desarrollo de las oportunidades, dentro de una sociedad en avance dinámico y constante, serán factores primarios que respaldarán la expansión del mercado delainformación.

5. Las industrias principales serán las intelectuales, el núcleo de lo que serán las industrias del conocimiento. Las industrias relacionadas con lainformación se añadirán a la estructura de industrias primarias, secundarias y terciarias como el grupo cuaternario.

6. La información será el eje del desarrollo socioeconómico, la producirán las unidades productoras de información; 2) aumentarála producción de información por parte de los usuariosy la información se acumulará; 3) esta información acumulada se expandirá con la utilización sinérgica y la utilización compartida; 4) la economía cambiará estructuralmente y de ser una economía de intercambio se convertirá en una economía sinérgica.

7. El objetivo será el principio fundamental de la sociedad, y la realimentación sinérgica que distribuirá las funciones para lograr un objetivo común, trabajará para mantener un orden en la sociedad.

8. El sujeto más importante de la actividad social, será la comunidad voluntaria, un grupo socioeconómico que se pueda dividir, en términos generales, en comunidades locales y comunidades unidas por la información.

9. Será ésa una sociedad civil voluntaria, caracterizada por la superioridad de su infraestructura, como una especie de sociedad que sume capital público, más recursos humanos y una estructura fundamental que agrupe el principio de la sinergia y el beneficio social.

10. Será una sociedad voluntaria, complementaria y multicentrada. Será funcional horizontalmente y mantendrá el orden social por medio delas funciones autónomas y complementarias de una sociedad civil voluntaria.

11. Persiguela realización del valor temporal para cada ser humano. El objetivo de la sociedad será que todo el mundo viva una vida que merezca la pena vivirse y busque mejores posibilidades futuras.

12. El sistema político pasará a ser una democracia participativa. Serála política de la participación de los ciudadanos, la política del autogobierno de los ciudadanos, basada en los acuerdos, la participación y la sinergia, y respetará las opiniones de las minorías. 
13. Serán los movimientos ciudadanos las fuerzas que estén detrás del cambio social, y sus armas serán los movimientos participativos y el litigio.

14. Los problemas de la sociedad de la información serán el shokk del futuro provocado por la incapacidad de la gentepara responder, de forma adecuada, a la rápida transformación de la sociedad.

15. El estado más avanzado de la sociedad de lainformación, será el de una sociedad que crea masivamente conocimientosy donde la información permitirá que cada individuo cree conocimiento.

16. El espíritu de la sociedad de la información será la globalización, una simbiosis en la que el hombre y la naturaleza puedan vivir juntos y en armonía, y cuya consistencia ética sea la estricta autodisciplina y la contribución social.

Masuda dice que para que se haga realidad la sociedad de la información, se deben contemplary analizar las fases del desarrollo informático, el empleo y la popularización de la computadora en una sociedad; según él existen cuatro fases que son las siguientes:

a. Fasedientífica Ésta tuvo lugar entre los años 1945-1970. En este periodo se comenzó a utilizar extensamente la computadora en proyectos nacionales; tales como, la defensa y la exploración espacial.

b. Fasegrencial. Esta fase de informatización comienza a utilizarse en la gestión empresarial tanto pública como privada, y transcurrió entre 1955-1980. Dicha fase se caracteriza por la expansión del Producto Nacional Bruto (PNB), ya que la informática se aplicó en áreas administrativasy empresariales, y la computadora aumentó la eficacia de ambas áreas.

c. Fasescial. En esta tercera fase la computadora se emplea para beneficio de la sociedad; el Bienestar Nacional Bruto (BNB) se convierte en el objetivo principal; la medicina y la educación pueden mencionarse como un ejemplo claro. En esta fase, las ciencias sociales e interdisciplinarias, combinadas con las redes de información, se utilizan ampliamente para solucionar problemas sociales.

Las aplicaciones de la computadora y las comunicaciones conforman lo que es la fase de la informatización al servicio de la sociedad como un todo. Masuda dice que esta fase se desarrolló en varios países industrializados en la década de los setenta.

d Faseindvidual. Masuda contempla que el desarrollo de esta fase es posible con la invención de los circuitos integrados, y se desarrolló entre 1975 y 2000. Todo el mundo podrá utilizar la información de las computadoras obtenida del sistema hombre máquina. En esta fase, la sociedad de la información habrá alcanzado el consumo masivo. "La rápida disponibilidad de información y conocimiento hará que florezca la creatividad humana; será el nivel más alto de informatización que yo llamo la sociedad de creación masiva de conocimiento." 48

48 Yoneji Masuya, qp at, p. 56. 
Tanto Masuda como D aniel Bell y Manuel Castells sostienen que las redes de información harán posible el desarrollo intelectual, y que la información no la ostentarán solamente las grandes organizaciones sino también los particulares.

Masuda afirma que las cuatro fases mencionadas anteriormente no necesariamente tienen que darse de manera secuencial paraintroducir a la siguiente, ya que algunas seguirán existiendo y desarrollándose independientemente.

En cuanto a la expansión espacial que tendrá la información, ésta pasará por tres fases, que son:

1. Espadolimitada La información en este espacio se refiere al uso restringido de la computadora por parte de una empresa, un gobierno o un domicilio particular, con un núcleo tecnológico no más avanzado que la computadora. Se podrá utilizar para capturar, almacenary recuperar datos estadísticos para los censos nacionales de todo tipo.

En el nivel social, existen servicios de recuperación de lainformación en bibliotecas y sistemas de enseñanza dirigidos por computadora en las escuelas. A nivel individual, existen las calculadoras electrónicas, computadoras domésticas y juegos electrónicos para televisión o computadora.

2. Espacioregianal naaional. Esto se refiere al alcance de las redes de información mediante el cual las personas, gobiernos e individuos realizarán sus intercambios y la utilización compartida de la información existente en las computadoras, las cuales tendrán que estar combinadas con circuitos de comunicaciones.

En el nivel social se incluyen los sistemas de control, prevención y eliminación de la contaminación y el sistema de asistencia médica regional de urgencia. En el nivel individual encontramos los teléfonos de teclado, la televisión por cable y la ciudad cableada. También existen sistemas de videotexto en países desarrollados, donde el suscriptor puede marcar un número de teléfono y recibir la información de la computadora en la pantalla de su televisor.

3. Espaaiogdbal. En esta fase se añaden las comunicaciones vía satélite ala tecnología de la información de la computadora y a los circuitos de comunicaciones. El nivel científico ya entró a esta fase, principalmente en el área espacial.

En el nivel social, la informatización aún está en una fase experimental como d PaaificEdurationandCommicationExpeiment, cuyo objetivo es poner en funcionamiento un sistema de información educativa en toda el área del Pacífico. Sin embargo, a nivel individual aún no existen ejemplos prácticos, pero en el futuro será posible para todas las personas del mundo hacer uso de sistemas autoeducativos, sistemas de información de bibliotecas, juegos competitivos y participar en un sistema global de votaciones.

Estos son algunos de los ejemplos que menciona Masuda, que podrán manifestarse y concretarse con la llamada sociedad de la información que aún está en construcción. (ver dagama 3) 


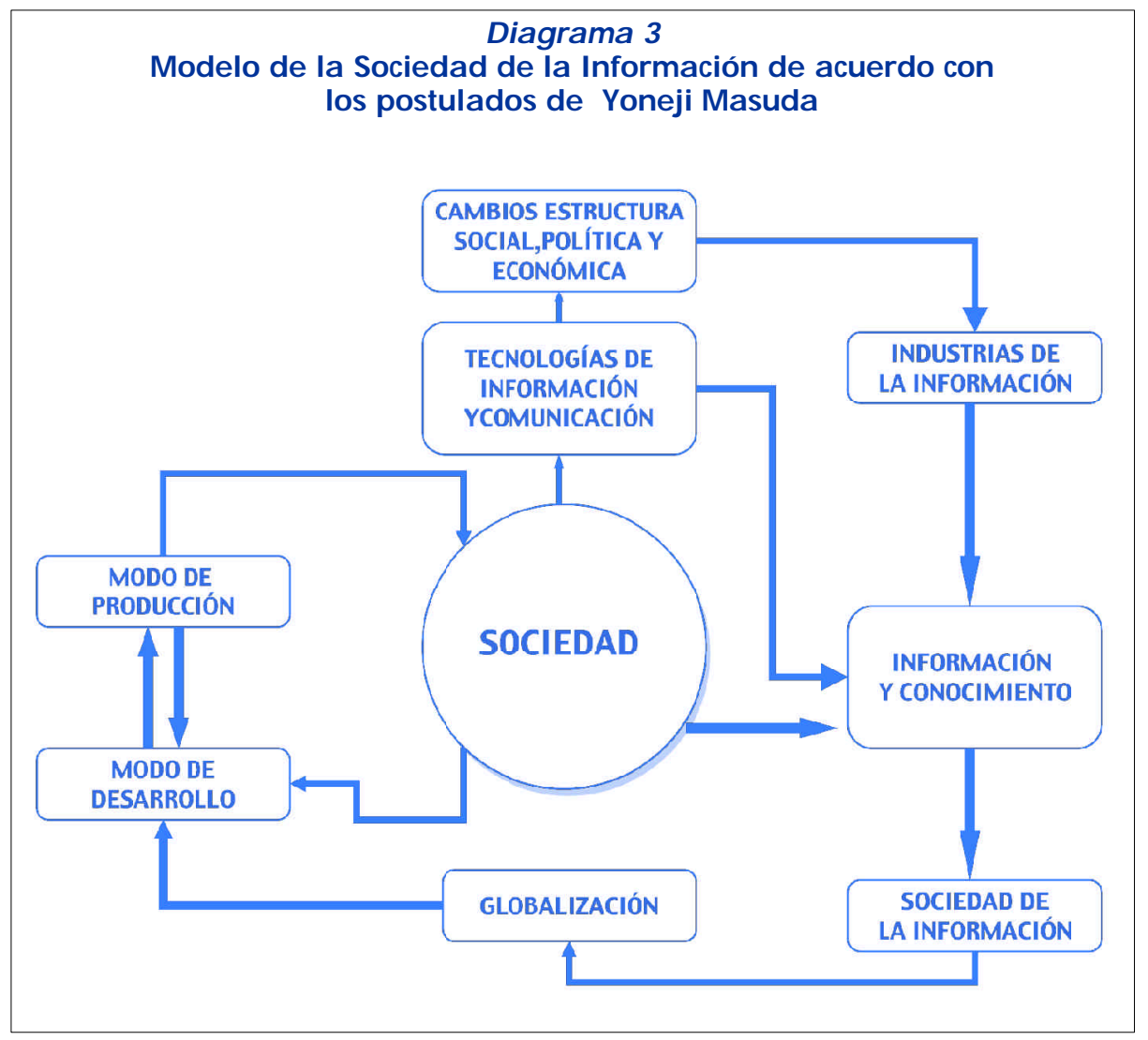

\section{Manuel $\mathrm{C}$ astells}

Manuel Castells parte de la idea de que los cambios históricos y sociales tienen una evolución dialéctica, y considera que el desarrollo tecno-económico juega un papel fundamental para agilizar los cambios en una sociedad. O bserva la dinámica delos cambios desde una perspectiva materialista y enfocada al aspecto económico, en las que las relaciones de producción y el avance tecnológico serán determinantes de la dinámica social.

Todas estas instancias de la sociedad interaccionan unas con otras enmarcando así los fenómenos sociales; la relación entre cambios tecnológicos y reestructuración económica son determinantes en el proceso de producción. ${ }^{49}$

Al hablar de la tecnología, Castells se refiere al tipo de relación establecida entre fuerza de trabajo y materia dentro del proceso de producción, a través de la interacción de medios de producción que utilizan energía y conocimiento. La productividad 49 Manuel Castells, qp at, p. 31. 
depende, a su vez, de la relación que se da entre el trabajo y la materia como una función del uso delos medios de producción, mediantela aplicación dela tecnología y el conocimiento.

Considera que la tecnología representa el uso del conocimiento, ya que éste ha sido empleado de diversas maneras.

En los modelos de desarrollo preindustriales el conocimiento se usa para organizar la movilización de mayores cantidades de trabajo y medios de producción. En el modelo industrial, el conocimiento se utiliza para proveer nuevas fuentes de energía y para reorganizar la producción. En el modo informacional de desarrollo, el conocimiento moviliza la generación de nuevo conocimiento como fuenteclave de la productividad a tra vés de su impacto sobre otros elementos del proceso de producción. 50

O pina que cuando las circunstancias históricas crean una convergencia entre cambio social y cambio tecnológico, asistimos a la creación de un nuevo paradigma tecnológico, el cual anuncia el advenimiento de un nuevo desarrollo.

Por mi parte considero que hay mucho de cierto en esta aseveración, ya que se puede tomar como ejemplo la Revolución Industrial, en donde el advenimiento y la aplicación de nuevas tecnologías de producción también causaron un gran impacto en las sociedades, lo que se advertía en el consumo, la facilidad para adquirir más productos, el abaratamiento de éstos, las revueltas sociales, el desempleo, las migraciones, y los cambios educativos y laborales, entre otros.

Actualmente las innovaciones científicas y tecnológicas las constituyen la microelectrónica, que se ha ido desarrollando mediante los descubrimientos del transistor, el circuito integrado, el proceso planary la computadora, entre otros, y tienen las siguientes características:

1. Las nuevas tecnologías centrales están concentradas en el procesamiento de la información, y la información y las tecnologías han sido importantes para efectuar nuevas operaciones o para realizar mejor las prácticas ya establecidas sobre la base de aplicación de nuevos conocimientos.

Las computadoras almacenan y organizan la información eficazmente y esto genera nueva información con base en la combinación e interacción de la información almacenada. Por otra parte, las telecomunicaciones permiten transmitir, intercambiar y enviar la información a otros lugares geográficos mediante los flujos de información.

2. Las computadoras son herramientas para el manejo de la información y de gran utilidad para procesarla, almacenarla y recuperarla.

Las nuevas tecnologías de información, transforman el modo en que producimos, consumimos, administramos, vivimos y morimos. No por sí mismas, pero sí como mediadoras de un conjunto más amplio de factores que determinan el comportamiento humano y la organización social.51

50 Manuel Castells, qp it, p. 34.

51 Manuel Castells, qp at, p. 40. 
Las nuevas tecnologías de información, se han enfocado a otras actividades sociales como educación, cultura, actividades laborales e incluso pasatiempos.

Las tecnologías de información como el teléfono, las computadoras, y las redes de comunicación, entre otras, han dado origen a un nuevo modelo de desarrollo; el proceso principal de la transición del desarrollo industrial al informacional, lo constituye el procesamiento de la información como actividad fundamental.

La transformación organizativa del modo de desarrollo, conlleva a la expansión de la tecnología de la información, cuyo efecto provoca ulteriores cambios organizativos. ${ }^{52}$

El modo informacional, del que habla Castells, está compuesto por el desarrollo tecnológico y la organización de la producción, lo que da origen a una nueva forma del capitalismo; las nuevas tecnologías de información han sido decisivas para la realización de tres procesos fundamentales en la reestructuración capitalista:

1. Incremento de los niveles de beneficio de diversas maneras:

a) Aumento de la productividad con base en la introducción de máquinas que utilizan la microelectrónica, y que transforman el proceso de producción.

b) Descentralización de la producción, así como la separación espacial de las diferentes unidades a través de las telecomunicaciones.

c) Posicionamiento del capital en una posición ventajosa en relación con el tra bajo, la automatización, las condiciones flexibles de fabricación y las nuevas tecnologías del transporte, que proveen a la administración de opciones que hacen posible la negociación con los sindicatos.

2. Las nuevas tecnologías de información constituyen un poderoso instrumento para aumentar las funciones de dominación y acumulación de la intervención estatal, esto se da en dos niveles:

a) El rápido cambio tecnológico vuelve obsoleto al actual sistema bélico, y sienta las bases para la expansión del Estado militarizado, involucrado en una carrera armamentista que sólo puede mantenerse con el apoyo de recursos estatales.

b) El papel estratégico jugado por la alta tecnología en el desarrollo económico, llevaal Estado a concentrarse en proveer las infraestructuras necesarias, minimizando su papel en las políticas de redistribución.

3. El proceso de internacionalización de la economía se da con base en los avances de las tecnologías de información. Las telecomunicaciones, la utilización de computadoras y otros materiales han creado la infraestructura material para una economía mundial.

52 Manuel Castells, qp at, p. 48. 


\section{Investigacón Biblicteedógica v. 15 N o. 31 julio/ diciembre de 2001}

El impacto de las tecnologías de información recae sobre la tecnología y la sociedad. Pero para que esto produzca formas equitativas, debe de existir una serie de factores intermedios, como el papel del Estado como fuerza motriz en el desarrollo de la innovación tecnológica de un país.

La evolución de los servicios, el ascenso de la economía de la información; el impacto de la automatización en el trabajo industrial y de oficina, y la interacción de todos estos elementos con el entorno espacial se articulan unos con otros..$^{53}$

Castells considera que no hay un sector servicios, sino que existe un número de actividades que emplean gente y generan ingresos que van más allá de las actividades de extracción y producción industrial, las cuales crecen en diversidad a medida que las sociedades aumentan y se hacen más complejas. Los llamados servicios crecieron con base en una variedad de demandas funcionales y presiones sociales, muchas de las cuales proceden de la movilización social y otras de concesiones políticas.

También dice que la fuerza de trabajo y el PIB se han venido incrementando en actividades de información, por lo que "nuestras economías han de categorizarse como informacionales; la producción del excedente proviene, principalmente, de la generación del conocimiento del procesamiento de la información necesaria." 54

El uso de computadoras y telecomunicaciones tienen relación con la dinámica que se ha establecido en el trabajo de oficinas y en la economía de la información en todas sus dimensiones. Lo que facilita las tecnologías de información es la interconexión de actividades, pues establecen las bases para incrementar cada vez más la capacidad de las industrias de servicios que intercambian información de manera continua.

Las redes de capital, trabajo, información y mercados enlazados mediante las tecnologías de información, unen a los pueblos y las localidades valiosas del mundo. 55

Las nuevas tecnologías de información como el fax, el teléfono, las computadoras y las telecomunicaciones, desempeñan un papel fundamental para hacer posible los flujos de información que trascienden el tiempo y el espacio, y hacen posible la existencia de la sociedad red. (Véase el modelo de Manuel Castells).

Según Manuel Castells la revolución de la tecnología de la información ha sido útil para llevar a cabo un proceso fundamental de reestructuración del modo de producción capitalista que comenzó a manifestarse en la década de los ochenta.

La perspectiva teórica que plantea Manuel Castells es que las sociedades están organizadas en torno a las relaciones de producción. La producción se define como la acción de la humanidad sobre la materia (naturaleza) para apropiársela y transformarla en su beneficio mediante la obtención de un producto.

La producción es un proceso social complejo debido a que cada uno de sus elementos se diferencia internamente a y que el trabajo está muy diferenciado y estratificado según el papel que desempeña cada trabajador en el proceso de producción.

53 Manuel Castells, qp it

54 Manuel Castells, qp at, p. 201.

55 Manuel Castells, "Entender Nuestro Mundo", Reista deOcidate, Madrid, 1998, no. 205, p. 14. 
El producto del proceso de producción lo utiliza la sociedad de dos formas: consumo y excedente. Las estructuras sociales interactúan con los procesos de producción mediante la determinación de las reglas para la apropiación, distribución y usos del excedente. Estas reglas constituyen modos de producción y estos modos definen las relaciones sociales de producción y determinan la existencia de clases sociales, las cuales se constituyen como tales mediante su práctica histórica.

En el modo de desarrollo agrario el aumento del excedente se debe al incremento de mano de obra y de recursos naturales, sobre todo la tierra.

En el modo de producción industrial la principal fuente de productividad es la introducción de nuevas fuentes de energía y la capacidad de descentralizar su uso durante la producción y los procesos de circulación.

En el nuevo mundo de desarrollo informacional, lafuente dela productividad estriba en la tecnología que genera el conocimiento, en el procesamiento de la información y en la comunicación de símbolos.

El procesamiento de la información se centra en la superación de la tecnología de este procesamiento como fuente de productividad, en un círculo de interacción de las fuentes del conocimiento de la tecnología y la aplicación de ésta para mejorar la generación de conocimiento y el procesamiento de la información. El informacionalismo se orienta hacia el desarrollo tecnológico, la acumulación de conocimiento y mayores grados de complejidad en el procesamiento de la información.

Castells concluye que no existe una homogeneidad en las sociedades que pueda describir lo que es una sociedad de la información; sin embargo sí se pueden mencionar rasgos fundamentales, lo que incluye dos precisiones importantes:

1. Las sociedades informacionales actuales son capitalistas, a diferencia de las sociedades industriales, donde muchas de ellas eran estatistas.

2. D ebe destacarse la diversidad cultural e institucional delas sociedades, todas ellas están afectadas por el capitalismo y el informacionalismo, y algunas de ellas, sobre todo las más desarrolladas, ya son informacionales aunque de tipos diferentes, en escenarios distintos y con expresiones culturales institucionales específicas. (Ver dagama 4 )

\section{CONCLUSIONES}

A partir de la década de los años sesenta, el desarrollo tecnológico aplicado alos medios de información y comunicación creó un nuevo paradigma, pues comenzó a incrementarse mucho el volumen de información en formatos que nunca antes habían existido.Y en el ámbito bibliotecológico se incrementaron las referencias de texto completo, y las imágenes con voz y el sonido, a tal grado que el significado mismo de la información adquirió otro sentido y fue objeto de estudio interdisciplinario.

Los trabajos relacionados con lainformación aumentaron de tal modo en los países desarrollados, como los que conforman El Grupo de los Siete, que el Producto 


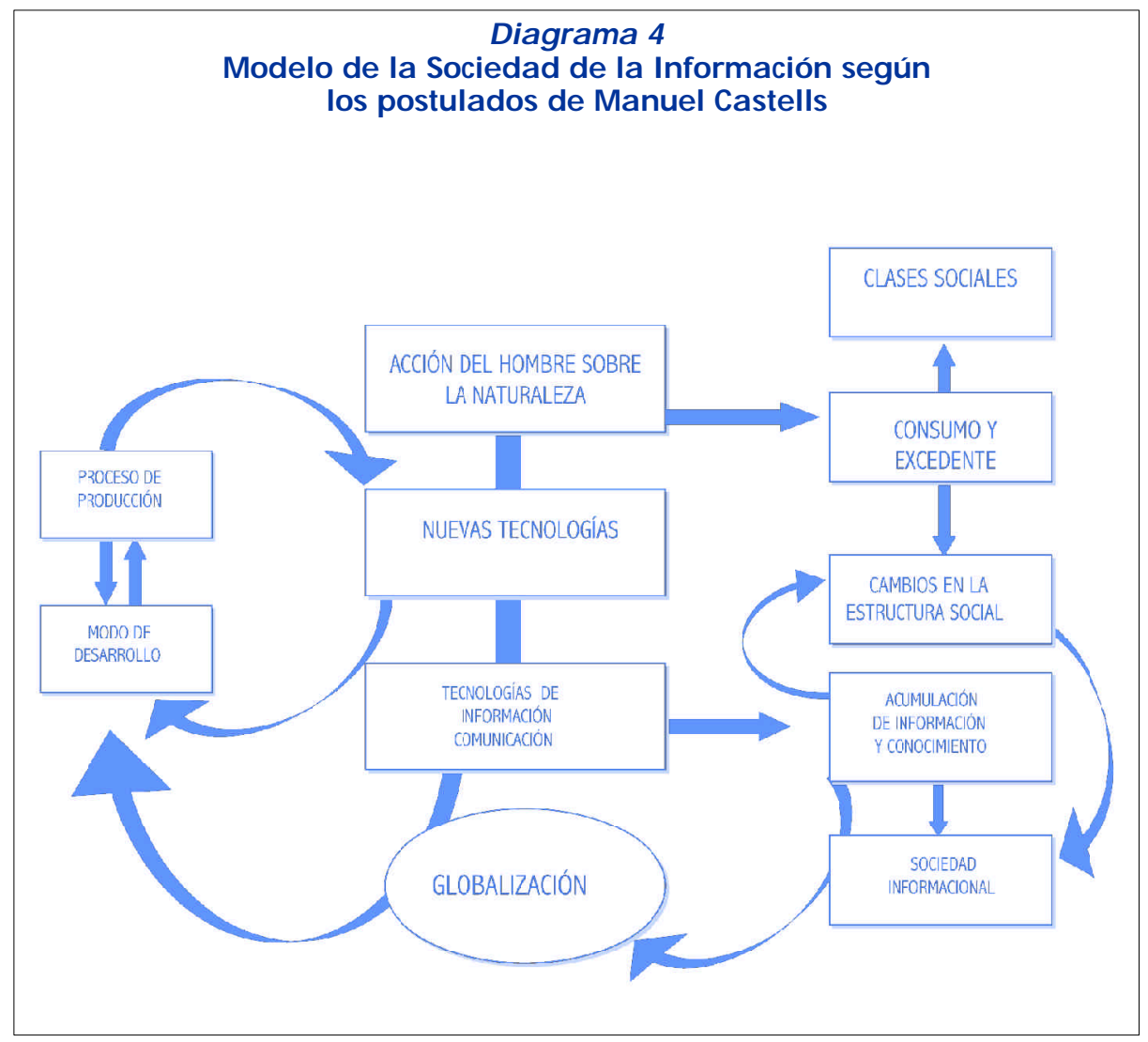

Interno Bruto y el número de personas ocupadas fue más alto que el existente en el sector servicios.

Con el empleo de las nuevas tecnologías de información y comunicación se hicieron realidad las redes de información y con ello varias comunidades compartieron recursos informativos y rompieron también las barreras territoriales y las distancias geográficas.

Las consecuencias sociales del uso de las computadoras semanifestaron en el trabajo, las diversas organizaciones, las industrias de computadoras, los sistemas deinformación, la cultura, el aprendizaje y la familia.

La utilidad de las tecnologías de la información y su enorme campo de extensión en la estructura social provocaron que varios gobiernos se interesarán en planear su desarrollo, y le encargaran a especialistas, informes para ver cómo estaban tecnológicamente y a qué se podía aspirar en estudios de prospectiva.

El concepto de socectaddelainfomacón ha sido estudiado desde una perspectiva estadunidense, en donde los pioneros fueron los estudios de Fritz Machlup, Marc Porat, y D aniel Bell, quienes advirtieron que las nuevas tecnologías de información 
han transformado las relaciones sociales y nuestro modo de observar el mundo. Bell dejó en claro que las nuevas tecnologías de información y comunicación han cambiado las relaciones sociales de producción, incrementado el PIB de las Naciones y creado un mayor número de empleos.

En Japón se desarrolló en Plan Jaadi y le fue encomendado a Yoneji Masuda, quien sostiene que el término sociedad de la información se debe a los avances tecnológicos, y que hacia allá se dirigen los países desarrollados, principalmente por el desarrollo tecnológico de las computadoras y las telecomunicaciones.

Masuda comparte la idea de Bell de que las nuevas tecnologías de información y comunicación han hecho realidad una producción masiva y sistematizada de información, la cual puede ser transferida a los lugares más lejanos del mundo en un mínimo de tiempo y acortar las barreras de distancia y de tiempo. El autor concluye que la información se ha construido paulatinamente en una industria que ha venido incrementando la economía de las naciones y que ha generando más ingresos que las industrias primarias, secundarias y terciarias.

Algo que no puede quedar al margen de esta temática es el hecho de que Manuel Castells recalca la función específica que juegan las nuevas tecnologías en el modo de producción informacional, donde la informática, la microelectrónica y las comunicaciones han hecho una realidad el aumento de la productividad, pero al mismo tiempo apunta que existe una desigualdad de distribución en las sociedades y pone el dedo en el renglón para que el desarrollo informacional sea planeado y desarrollado.

En el caso de México, país más consumidor que productor de nuevas tecnologías, para no quedar rezagado con el advenimiento de la sociedad de la información, sería necesario que generara estudios patrocinados por el gobierno junto con la iniciativa privada, para analizar nuestra situación ante las potencias que han desarrollado este tipo de perspectiva, y dejar claro qué es lo que necesitamos para no quedarnos a la zaga, ya que hasta ahora no se le ha dado gran importancia al desarrollo de la sociedad de lainformación, ni existen fuentes suficientes que contabilicen cómo havenido dándose el crecimiento de las actividades de información en las últimas tres décadas.

Hasta ahora se puede ver cómo se concreta la sociedad de la información en sociedades desarrolladas, y que éstas serán un modelo a seguir para las sociedades menos desarrolladas, como México, las cuales por supuesto, tendrían que apegarse a sus propias características y objetivos.

El cambio tecnológico haalterado profundamentela naturaleza y el carácter central que desempeña la actividad industrial en la sociedad. El crecimiento de la industria y los servicios no es ya el ímpetu principal del desarrollo social y está siendo reemplazado por una fuerza todavía no definida, basada en la información.

O tros elementos implicados para explicar la conformación de una sociedad de la información han sido la educación, la economía y la globalización, pero ninguno de estos elementos por sí solo ha podido explicar la transición de una sociedad industrial a una sociedad de la información. No obstante considero que la interrelación de estos elementos nos orienta parainterpretar en qué consiste este tipo de sociedad. 


\section{BIBLIOG RAFÍA CON SULTADA}

Bell, D aniel. ElAdkenimientodelaSaciedadPostindustrial. UnIntentodeProgno sis Social. Madrid, Alianza, 1976, 578 pp.

Castells, Manuel. HighTechndogy, Spaceand Socidy. California, Sage, 1985, $374 \mathrm{pp}$.

- - - La Ciudad Infomadional: Temdoǵas dela Infomacón, Restururación Económicayd ProcesoUrbanoRegional. Madrid, Alianza, 1995, 412 pp.

- - -. TheRise of theNewark Soidy. London, Blackwell Publisher, 1996, $262 \mathrm{pp}$.

- - -.LaEradelaInfomadón: Economáa SociedadyCultura, V dumenI. LaSo ȧeadRed, México, Siglo XXI, 1997, 576 pp.

- - -. "Entender Nuestro Mundo", Reista deOcidante, 1998, no. 205, pp. 8-32.

- - - . đal. NuerasTemdoǵas, EconomáaySociedadenEspaña Madrid: Alianza, 1986, 219 pp.

- - - and Yuko, Aoyama, "Paths towards the informational society: employment structure in G - 7 countries, 1920 -1990". Intemetional Labour Reuiew, 1994, vol. 133, no. 1, pp. 5-34.

Cazadero, Manuel. LasRevduciones Industrales México: Fondo de Cultura Económica, 1996, 229 pp.

Clark, Colin. LasCondidiones da ProgreoEconómica Vol. 2. 3ạ. Ed. México, Alianza, 1980, 266pp.

D uff, A. S. "D aniel Bell theory of the Information Society" . En Jaumal of Information Sociey, Vol. 24 núm. 6, 1998 pp. 373-399.

Giddens, Anthony, ConseeuenaasdelaModamidad Madrid, Alianza Universidad, 1994, $166 \mathrm{pp}$.

Maccarthey, Thomas A. TheCritical Theory ofJurgen Habemas Cambridge, Mass. The MIT Press, 1978, $466 \mathrm{pp}$.

Machlup, Fritz. TheProductionandDistribution of Knowkedgein theUnitedStates New Jersey, Princenton University, 1971, 416 pp., il.

Martin, Stana B. "Information Technology, Employment, and the Information Sector: Trends in Information Employment 1970-1995", en Jamal of theAmerican Socidyfor InformationSaience, 1998, Vol. 49, No. 12, pp. 1053-1069.

Martin, William J. TheGldbal Information Sociey. London, Aslib, G ower, 1997, $237 \mathrm{pp}$.

Moore, Nick, "La Sociedad de la Infomación", UNESCO RepateMundial SdoreInfomacón, 1997-1998, New Y ork: UNESCO , 1998, 284 pp.

Naisbitt, John, Gldbel Paradbx: theBigger theWoddEconomy, theMorePoweful its Smallest Playes, New York: William Morrow, 1994, 304 pp.

Porat, Marc Uni, TheInfomation Economy: Definition and Measurement U.S.: D epartment of Commerce, 1977, 242 pp.

Reyna Schement, Jorge, CompeingV isions, Complex Realities Social Aspetsof theInformation Saidy, New Jersey, Ablex Publishing, 1987, 167 pp.

Webster, Frank, TheoriesoftheInformationSocidy, Londres, Routledge, 1995, $215 \mathrm{pp}$. 